\title{
Reproductive possibilities for balanced translocation (14) carriers in families with partial trisomy of proximal $14 \mathrm{q}$
}

\author{
G Valkova, M Stefanova
}

\begin{abstract}
Two cases of $14 \mathrm{q}$ proximal partial trisomy in sisters from the same family are reported. Clinical features included craniofacial dysmorphism, skin depigmentation, slight anomalies of the limbs, muscular hypertonia, and physical and mental retardation. The third sister had an abnormal phenotype, different from that of her sibs, and proved to be a carrier of a balanced translocation $(2 ; 14)(q 36 ; q 21)$ inherited from their phenotypically normal mother. (f Med Genet 1993;30:73-5)
\end{abstract}

The first case of proximal trisomy $14 \mathrm{q}$ was reported by Allderdice et $a l^{1}$ in 1971. Thirtythree cases have since been described and their clinical and cytogenetic features have been summarised by Faugeras et al. ${ }^{2}$ The present paper reports two recent cases of familial partial trisomy of proximal $14 \mathrm{q}$ in two sisters resulting from malsegregation and formation of unbalanced gametes in their mother, who is a carrier of a balanced $(2 ; 14)(\mathrm{q} 36 ; \mathrm{q} 21)$ translocation.

\section{Case report}

CASE 1

A girl was born of the second normal pregnancy who had facial dysmorphism, bilateral simian creases, and physical and mental retardation. Cytogenetic analysis was performed at the age of 9 months in September 1969.

Chromosome studies on cultured lymphocytes using routine Giemsa staining showed an additional small acrocentric, the identity of which remained undetermined because of the death of the child at the age of 1 year.

CASE 2

Another girl was born of the third normal pregnancy when the parents were relatively advanced in years (mother 40 , father 46 ). She weighed $2800 \mathrm{~g}$, height $50 \mathrm{~cm}$. Physical and mental retardation was noticed at 4 to 5 months.

The child was first examined at the age of 13 years and severe physical and mental retardation was present. She weighed $13 \mathrm{~kg}$ and was $100 \mathrm{~cm}$ tall. She could not sit or walk, turn over by herself, speak, or understand what was said to her. Her IQ was found to be below 20. There was a high degree of generalised muscular hypertonia in the flexure groups and craniofacial dysmorphism (fig 1) including microcephaly (OFC $48 \mathrm{~cm}$ ), low forehead, hypotelorism, horizontal palpebral fissures, enophthalmos, prominent nose with a narrow nasal bridge, inverted nostrils, a poorly defined philtrum, thin lips, irregularly implanted teeth with a protruding right canine, retrognathia, low set ears with small lobules, a short neck, and a funnel shaped dimple $0.6 \mathrm{~cm}$ in depth on the skin over the sacrum. There were also prominent spinal processes on $\mathrm{T} 12$ and $\mathrm{L} 1$ without distortion of the vertebral column. Bilateral simian creases and expressed lines were present on both sides of the palms. Isodactylism of the left 2nd, 3rd, and 4th toes was found, and on the right the 4 th toe overlapped the $3 \mathrm{rd}$. The internal organs and genitalia were reported to be normal. At the age of 13 years there was no sign of puberty. No frequent infections had been recorded.

Cytogenetic studies on cultured lymphocytes after $G$ banding showed a 47,XX, $+14 q$ prox karyotype.

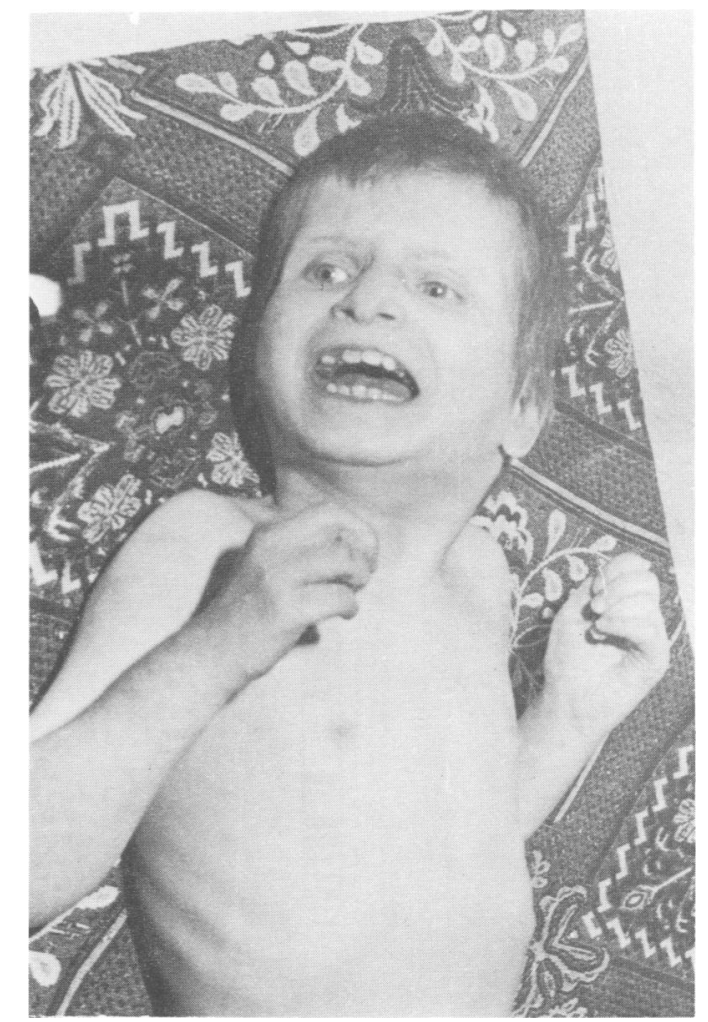

Figure 1 Case 2 aged 13 years. 


\section{Family history}

The parents were phenotypically normal, and the father had a normal karyotype; however, the mother showed $46, \mathrm{XX}, \mathrm{t}(2 ; 14)(\mathrm{q} 36 ; \mathrm{q} 21)$ (fig 2). The same karyotype was also found in their oldest daughter, the first child of the family, who had a history of two spontaneous abortions and was 22 years old at the time of the study. Immediately after her birth it was found that she had a left sided cleft of the upper lip, a midline fissure of both the soft and hard palates, and facial dysmorphism, including pronounced hypertelorism, bilateral epicanthic folds, exophthalmos, a broad nasal bridge, and simian creases on the right palm. When examined at the age of 22 years, she showed normal physical, mental, and sexual developmemt. The lip and palate defects had been surgically repaired. Depigmentation of a lock of hair above the forehead occurred at the age of 10 years. During her third pregnancy, prenatal diagnosis was performed and after a normal fetal karyotype had been established a healthy child was delivered (fig 3 ). Study of the
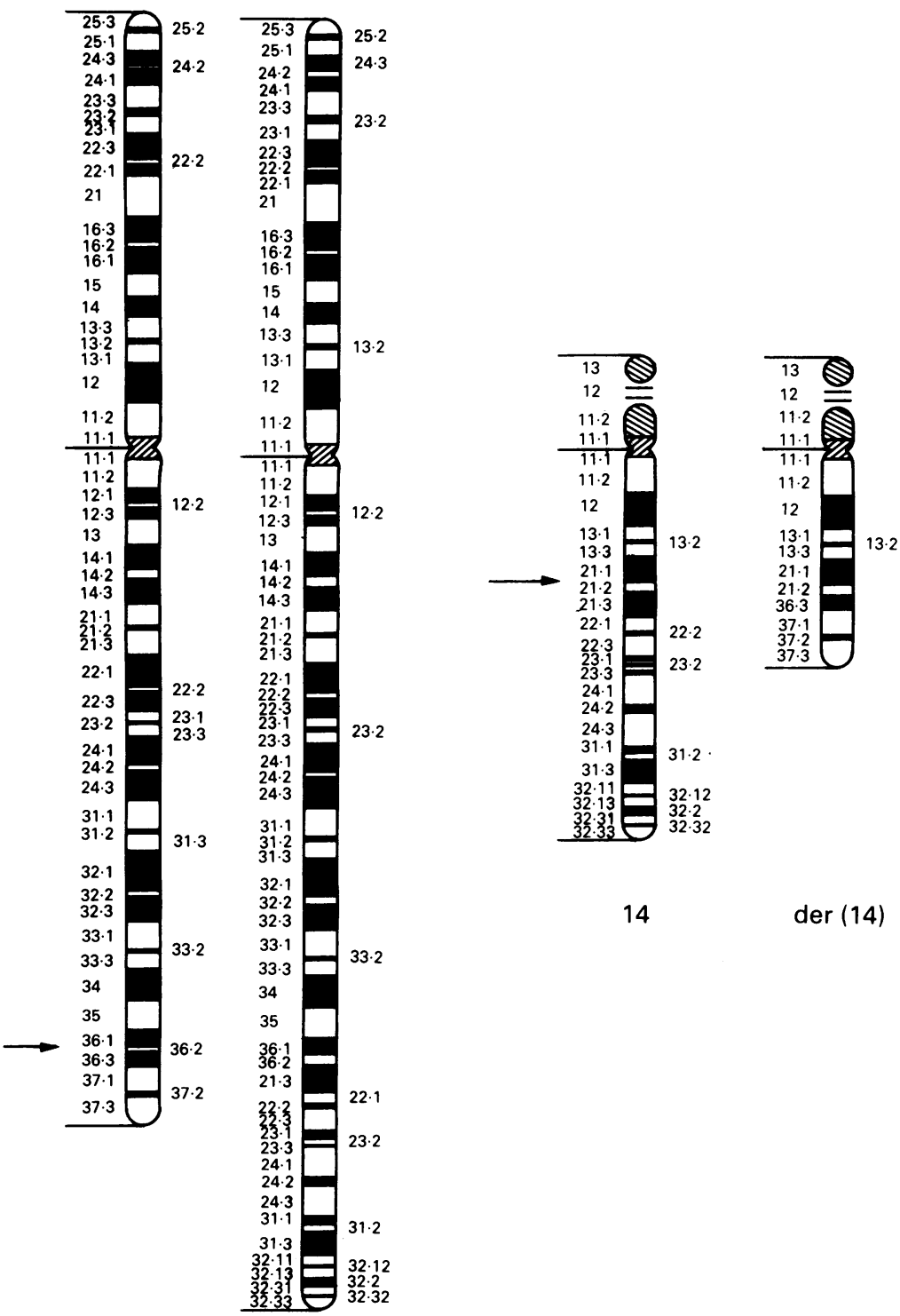

2

der (2)

Figure 2 Diagram of the balanced translocation $(2 ; 14)$.

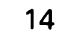

$\operatorname{der}(14)$

pedigree showed a spontaneous abortion in her dead grandmother. Her mother's sister had a normal karyotype.

\section{Discussion}

The present cases show various types of segregation in two female $2 ; 14$ balanced reciprocal translocation carriers. The zygotes formed by the mother's gametes resulted from alternate segregation in the first pregnancy and 3:1 segregation in both probands. The daughter's first two pregnancies were spontaneous abortions and the type of segregation is unknown as no cytogenetic studies were possible. Aneuploid segregation in the maternal gametes might well have occurred. A 2:2 segregation was present during the third pregnancy.

This family prompted us to review published data ${ }^{3-26}$ concerning familial inherited partial trisomy of proximal $14 \mathrm{q}$ and analyse the chromosome segregation in the balanced translocation carriers in these families. The summarised data for men and women carriers are shown in fig 4.

Out of a total of 25 women carriers, 61 pregnancies occurred and 20 children were delivered resulting from alternative segregation. Six of these had a normal karyotype $(9.8 \%$ of all pregnancies) and 14 had a balanced translocation (22.9\%); 3:1 segregation resulted in 26 children, 25 of them having partial trisomy of proximal $14 \mathrm{q}(40.9 \%)$ and one having partial monosomy of proximal 14q. There were 15 spontaneous abortions accounting for $24.5 \%$ of the total. Out of a total of 12 male balanced translocation carriers the data were as follows: nine zygotes had a normal

III
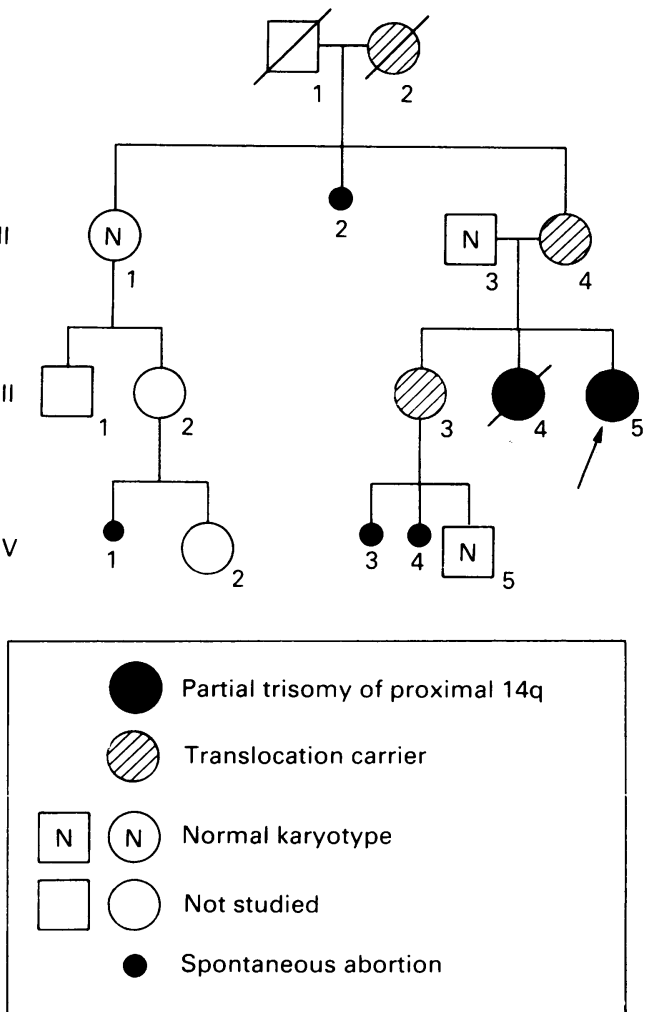

Figure 3 Family pedigree. 


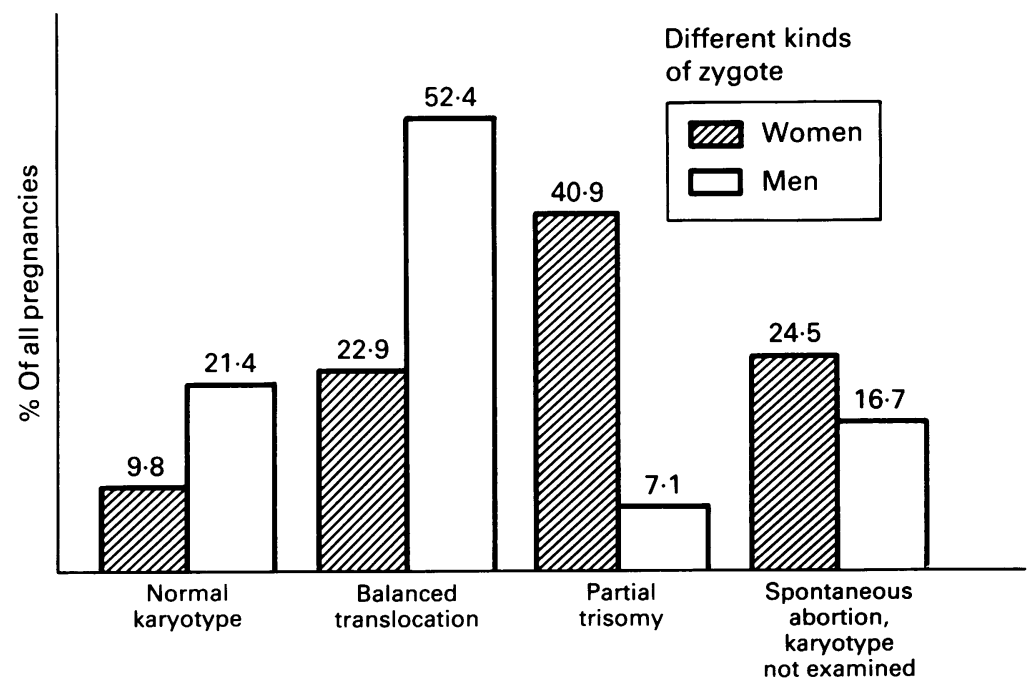

Figure 4 Diagram of segregation type. the existing phenotypic picture of the $14 \mathrm{q}$ proximal partial trisomy syndrome. The sibs described are two of the few cases of this syndrome to live to such an advanced age (the oldest child was 18 years old and showed no pubertal development). ${ }^{21}$

1 Allderdice PW, Miller OJ, Miller DA, Breg WR, Gendel E, Lelson C. Familial translocation involving chromosomes 6,14 and 20 identified by quinacrine fluorescence. 6, 14 and 20 identified by

2 Faugeras C, Barthe D. Trisomie 14 proximale. Ann Pediatr (Paris) 1986;33:55-8.

3 Abelovich D, Yagupsky P, Bashan N. Meiotic dysfunction in a mother with a balanced translocation, $46, X X, t(5 ; 14)(\mathrm{p} 15 ; \mathrm{q} 13)$ resulting in tertiary trisomy and tertiary monosomy offspring. Am $\mathcal{f}$ Med Genet 1982;12:83-9.

4 Coco KK, Penchaszadeh VBP. Partial trisomy $14 \mathrm{q}$ and familial translocation $(2 ; 14)(\mathrm{q} 12 ; \mathrm{q} 13)$. Ann Genet (Paris) 1977;20:41-4.

5 Cohen MM, Rosenmann A, Dagan J, Legum C. Partial trisomy D: a diagnostic and cytogenetic dilemma. $f$ Med Genet 1976;13:535-7.

6 Cottrall K, Magrath I, Bootes JAH. A case of proximal 14 trisomy with pathological findings. $\mathcal{f}$ Ment Defic Res $1981 ; 25: 1-6$.

7 Fawcett WA, McCord WK, Francke U. Trisomy 14q-. Birth Defects 1975;2(5):223-8.

karyotype $(21 \cdot 4 \%), 22$ had a balanced translocation $(52.4 \%)$, and three resulted from a $3: 1$ unbalanced segregation (partial trisomy) $(7 \cdot 1 \%)$. Seven $(16 \cdot 7 \%)$ pregnancies ended in spontaneous abortion and in one pregnancy $(2.4 \%)$ a child with a mosaic balanced translocation/partial trisomy of proximal $14 \mathrm{q}$ was delivered. Abortions by request and ectopic pregnancy were not included. A significant difference in reproduction between balanced translocation carrier men and women was evident.

In order to evaluate the difference in reproduction of men and women, an alternative analysis was applied to determine the significance level. In the case of zygotes with a balanced karyotype and a partial trisomy, there was a significant difference in the formation of zygotes of balanced karyotype and partial trisomy by men and women $(p<0.01)$. The balanced translocation carrier men formed balanced translocation zygotes considerably more often than the same carrier women, while the $14 \mathrm{q}$ proximal partial trisomy zygotes were more often formed by female carriers than by male carriers. The possibility of the offspring of male $14 \mathrm{q}$ proximal partial trisomy carriers being miscarried, that is, being transferred to the group of spontaneous abortions, was ignored since the difference in aborted zygotes formed by male and female carriers was not significant (significance level $\mathrm{p}>0 \cdot 1$ ). There was no significant difference in conceiving children of normal karyotype by male and female carriers.

These data enabled us to conclude that the risk of conceiving a child with partial trisomy of proximal $14 \mathrm{q}$ was considerably higher in female balanced translocation carriers than in males.

The cases reported here confirm and add to
8 Fried K, Goldberg MD, Kosenblatt $M$. Proximal 14 trisomy $46, \mathrm{XX},-22+\operatorname{der}(14) \mathrm{t}(14 ; 22)$ (q21;q11) mat. Tera-

9 Fryns JP, Cassiman JJ, Van Den Berghe H. Tertiary partial 14 trisomy 47,XX, +14q. Hum Genet 1974;24:71-7.

10 Giorgi PL, Tarantino E, Formica A, Dallapiccola B. Trisomia parziale terziaria $14 \mathrm{p}$ ter $\rightarrow \mathrm{q} 21$ da traslocazione familiare + $(10 ; 14)(\mathrm{p} 15,2 ; \mathrm{q} 21)$. Acta Med Auxol 1979;11:615.

11 Kovacs GY, Mihai C. Tertiary trisomy 14q-, due to a paternal balanced translocation $46, \mathrm{XX}, \mathrm{t}(1 ; 14)$ (q44; $\mathrm{q} 22)$. Hum Genet 1979;49:175-8.

12 Lancet $M$, Sindel L, Segal I. Familial 5/14 translocation with triple $X$ and 47,XY $+14 q-$. Clin Genet 1981;20:40-

13 Mendez HMM, Paskulin GA, Breda DJ. Syndrome of partial proximal trisomy 14q; report of a case and review of the literature. Am 7 Med Genet 1983;35:107A

14 Miller JQ, Willson K, Wyandt H, Jamarillo MA, McCon1979;16:60-5

15 Pfeiffer RA, Buttinghaus K, Struck H. Partial trisomy 14 following a balanced reciprocal translocation $\mathrm{t}(14 \mathrm{q}-; 21 \mathrm{q}+)$. Humangenetik 1973;20:187-9.

16 Raoul O, Rethore MO, Dutrillaux B, Michon Z, Le Jeune J. La trisomie partielle 14q.I. Trisomie partielle $14 \mathrm{q}$ due a une translocation maternelle $\mathrm{t}(10 ; 14)(\mathrm{p} 15.2 \mathrm{q} 22)$. Ann Genet (Paris) 1975;18:35-9.

17 Ray M, Hunter AGW, Sachdela RK, Christie N. Partial trisomy 14 with a $46, \mathrm{XY},-13,+\operatorname{der}(14),+(13 ; 14)(\mathrm{q} 12 ; \mathrm{q}-$ 22)mat karyotype. Ann Genet (Paris) 1979;22:47-9.

18 Reiss JA, Wyandt HE, Magenis KE, Lovrien EN, Itecht F. Mosaicism with translocation; autoradiographic and fluorescent studies of an inherited reciprocal translocation orescent studies of an inherited reciprocal trisomy $47, \mathrm{XY},\left(14 \mathrm{q}^{-}\right)$) and translocation $\mathrm{t}\left(9 \mathrm{p}+; 14 \mathrm{q}^{-}\right)$ in mother and brother. $\mathcal{f}$ Med Genet 1972;9:367-73.

20 Simpson JM, Zellweger H. Partial trisomy $14 q^{-}$and parental translocation of nol 4 chromosome. 7 Med Genet 1977;14:124-7.

21 Smith A, Den Dulk G, Elliott G. A severely retarded 18 year old boy with tertiary partial trisomy 14. f Med Genet 1980;17:230-2.

22 Soudek D, Hunter P, O'Shaughnessy S, Simpson N, Sondek V. Familial translocation $t(8 ; 14)$ with a case of tertiary trisomy, +14q-. Birth Defects 1978;14:309-15.

23 Tada $H$, Shinohava $T$, Miyata $H$. A case of partial 14 trisomy, 47, XX, $+\operatorname{der}(14), \mathrm{t}(9 \mathrm{p}+; 14 \mathrm{q}-)$. fpn $\mathcal{f}$ Hum Genet 1982;27:283-8.

24 Turleau C, De Grouchy J, Bocquentin F, Roubin M, Chavin-Colin F. Trisomie 14q partielle par translocation maternelle (12-14)(q24.4;q21). Ann Genet (Paris) maternelle 14 : $12-1$

25 Yeatman GW, Riccardi VM. Partial trisomy of chromo-

26 Young SR, Donovan DM, Greer HA, Burch K, Potter DC Tertiary trisomy $47, \mathrm{XX},+14 \mathrm{q}-$, resulting from maternal balanced translocation, 46,XX,t(14;16)(q11;q24). Hum Genet 1976;33:331-4. tology 1980;21:309-12. nell $T$. Familial partial trisomy 14. F Med Genet

19 Short EM, Solitare GB, Breg WK. A case of partial 14 some 14: $\left(+14 q^{-}\right)$. Birth Defects 1976;XII(5):119-24. 